\title{
Comparison of Carbohydrate Force Fields in Molecular Dynamics Simulations of Protein-Carbohydrate Complexes
}

Anita Plazinskaa, Wojciech Plazinskib,*

${ }^{a}$ Department of Biopharmacy, Medical University of Lublin

Chodzki 4a, 20-093 Lublin, Poland

b Jerzy Haber Institute of Catalysis and Surface Chemistry

Polish Academy of Sciences

Niezapominajek 8, 30-239 Krakow, Poland

* Corresponding author; e-mail: wojtek_plazinski@o2.pl

\section{Supporting Information}

Tab. S1. The compositions and the initial dimensions of the simulation boxes for all the systems considered in our study.

\begin{tabular}{|c|c|c|c|c|}
\hline & \multicolumn{4}{|c|}{ Carbohydrate-protein complexes } \\
\hline System & Water molecules & Ions & Box type & Box vector lengths $\left[\mathrm{nm}^{3}\right]$ \\
\hline 1af6/Suc & $\sim 9900$ & $15 \times \mathrm{Na}^{+}$ & dodecahedron & $8 \times 8 \times 8$ \\
\hline 1i82/Cel & $\sim 7100$ & $5 \times \mathrm{Na}^{+}$ & dodecahedron & $7 \times 7 \times 7$ \\
\hline $1 \mathrm{i} 8 \mathrm{a} / \mathrm{Glc}$ & $\sim 7100$ & $5 \times \mathrm{Na}^{+}$ & dodecahedron & $7 \times 7 \times 7$ \\
\hline 1ogd/Rib & $\sim 5700$ & $7 \times \mathrm{Na}^{+}$ & dodecahedron & $6.5 \times 6.5 \times 6.5$ \\
\hline 1z3v/Lac & $\sim 11800$ & $15 \times \mathrm{Na}^{+}$ & dodecahedron & $8.4 \times 8.4 \times 8.4$ \\
\hline 2aac/Fuc & $\sim 7200$ & $3 \times \mathrm{Na}^{+}$ & dodecahedron & $7 \times 7 \times 7$ \\
\hline 2arc/Ara & $\sim 7200$ & $3 \times \mathrm{Na}^{+}$ & dodecahedron & $7 \times 7 \times 7$ \\
\hline & \multicolumn{4}{|l|}{ Carbohydrates } \\
\hline System & Water molecules & Ions & Box type & Box dimensions $\left[\mathrm{nm}^{3}\right]$ \\
\hline all & $\sim 2250$ & - & rectangular & $4.1 \times 4.1 \times 4.1$ \\
\hline
\end{tabular}



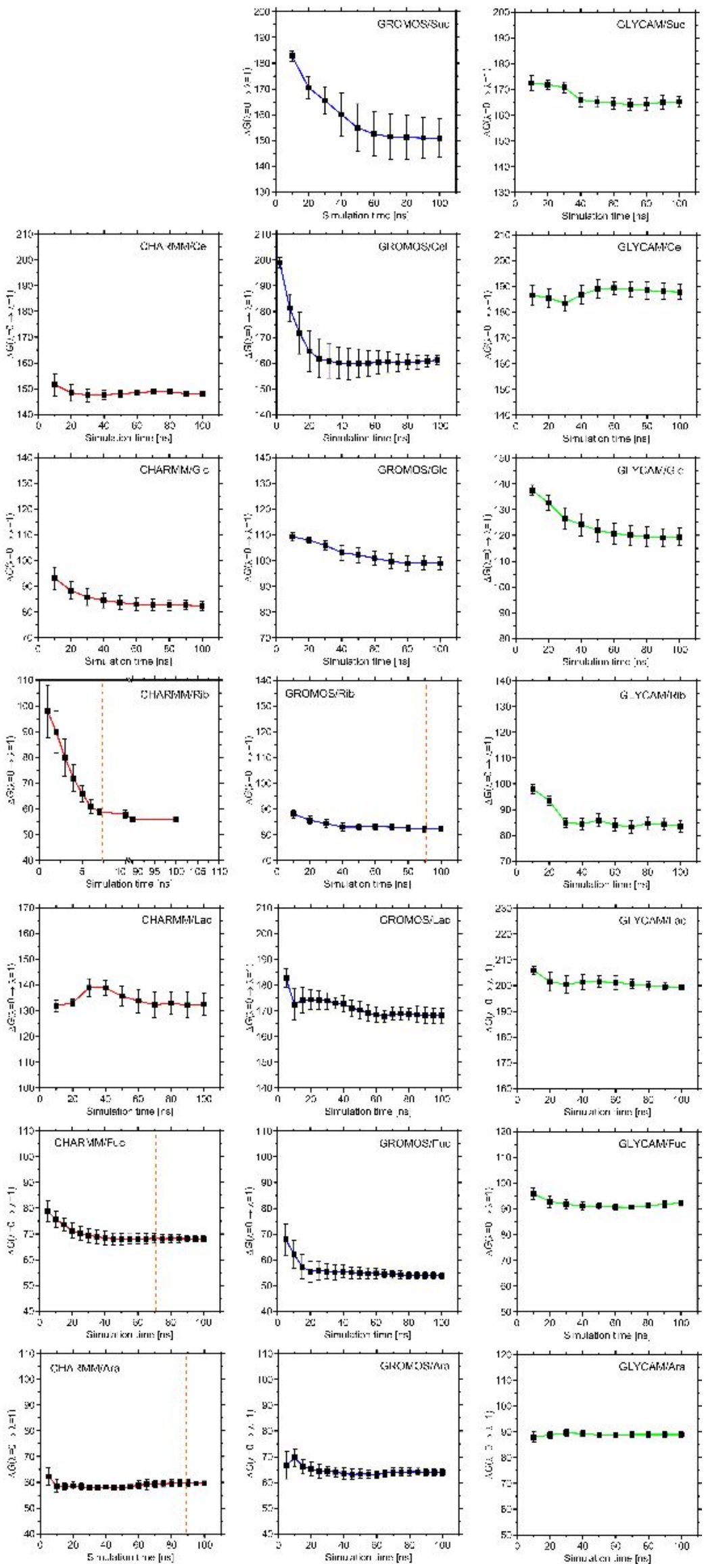

Fig. S1. The plots showing the convergence of the free energy changes upon decoupling the carbohydrate molecule from the protein-containing complex. 

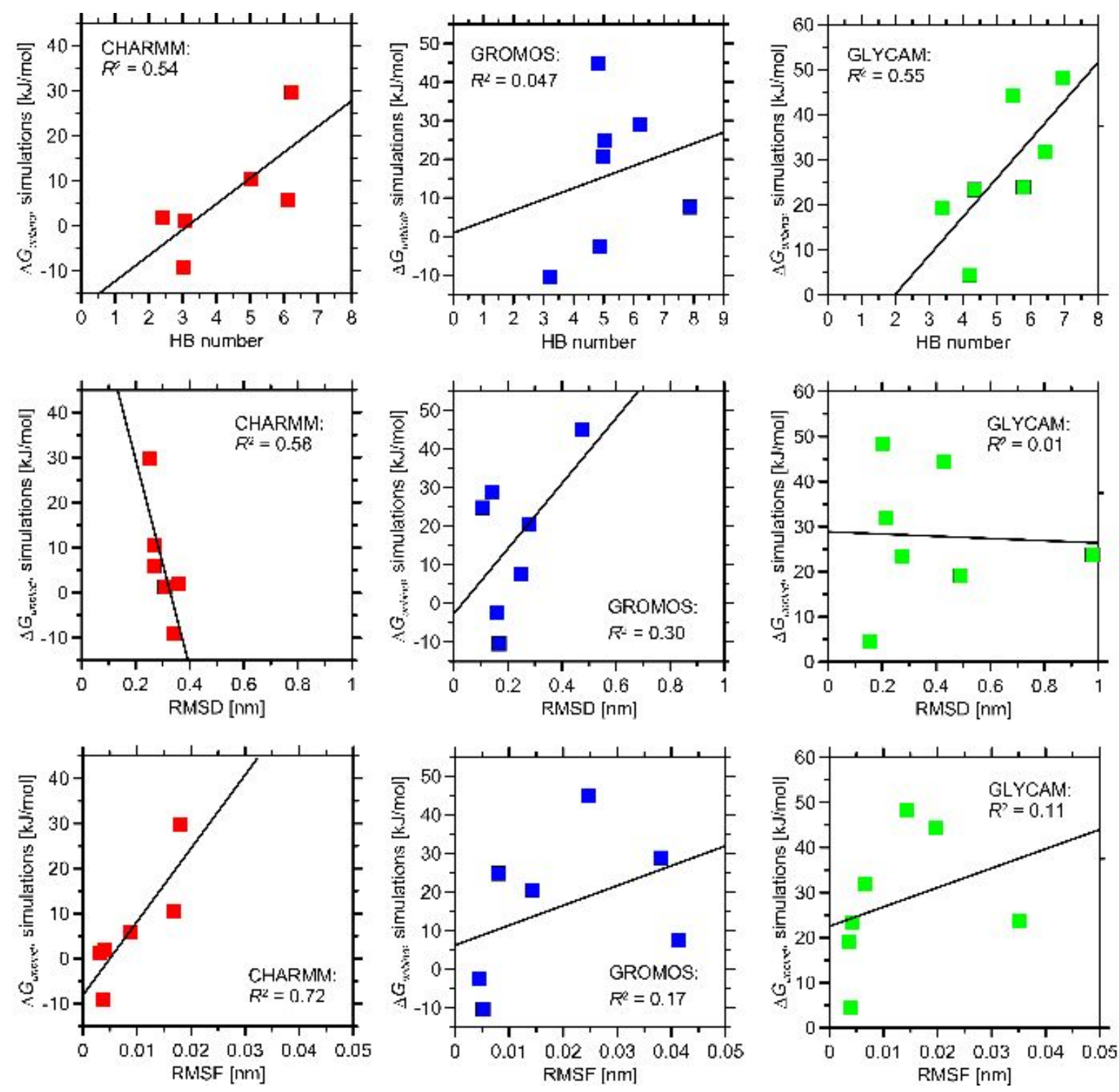

Fig. S2. The correlation between structural descriptors and carbohydrate-protein unbinding free energies calculated within different force fields. Details are given in the main text. 